\title{
Electron-Deficient Heteroacenes that Contain Two Boron Atoms: Near-Infrared Fluorescence Based on a Push-Pull Effect
}

\author{
Masato Ito, ${ }^{[a]}$ Mika Sakai, ${ }^{[a]}$ Naoki Ando, ${ }^{[a]}$ and Shigehiro Yamaguchi*[a,b]
}

[a] M. Ito, M. Sakai, Dr. N. Ando, Prof. Dr. S. Yamaguchi

Department of Chemistry, Graduate School of Science, and Integrated Research Consortium on Chemical Sciences (IRCCS), Nagoya University Furo, Chikusa, Nagoya 464-8602, Japan

[b] Prof. Dr. S. Yamaguchi

Institute of Transformative Bio-Molecules (WPI-ITbM), Nagoya University

Furo, Chikusa, Nagoya 464-8601, Japan

E-mail: yamaguchi@chem.naogya-u.ac.jp

\begin{abstract}
Electron-deficient heteroacenes that contain two tricoordinate boron atoms in their acene skeletons and planarized phenyl ether moieties at their periphery were synthesized via the borylation of silicon-bridged precursors. X-ray crystallographic analysis revealed quinoidal structures, which give rise to two-step reversible redox processes for both the reduction and oxidation. These compounds exhibit intense absorption and sharp fluorescence bands with vibronic structures in the near-infrared (NIR) region. These properties originate from the push-pull effect along the long axis of the molecule derived from the electron-donating ether moiety and the electron-accepting boron moieties. Of particular note is the NIR emission of the thienothiophene-centered heteroacene, which has a maximum at $952 \mathrm{~nm}$ with a narrow band width of $309 \mathrm{~cm}^{-1}$ in cyclohexane. A Franck-Condon analysis revealed the crucial role of the sterically less-hindered thienothiophene spacer in achieving this sharp emission band.
\end{abstract}

\section{Introduction}

Embedding main-group elements into $\pi$-conjugated skeletons is a robust strategy for producing novel $\pi$-electron materials ${ }^{[1]}$ The specific orbital interactions or inductive effects of the main-group moiety alter the electronic structures of the skeletons. ${ }^{[2]} \mathrm{A}$ representative example of a group of compounds that is strongly influenced by main-group effects is xanthene dyes. The replacement of the oxygen atom at the 10-position of fluorescein or rhodamine with various main-group elements results in substantial bathochromic shifts of the absorption and emission wavelengths (Figure 1a). ${ }^{[3]}$ In particular, we have recently reported a boron-substituted fluorescein derivative that exhibits absorption and emission bands in the near-infrared (NIR) region, which were red-shifted by more than $300 \mathrm{~nm}$ compared to those of the parent oxygen-containing fluorescein. ${ }^{[4]}$ To enhance the effect of this boron-substitution strategy, we envisaged the integration of two xanthene skeletons into the five-ring fused $\pi$ scaffold 1, which should be of interest as a boron-embedded pentacene (Figure 1a). (a)

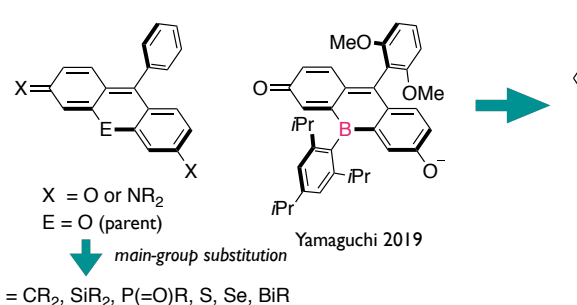

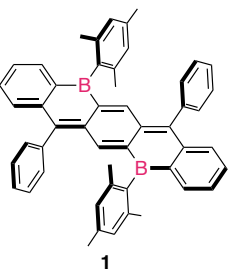

(b)
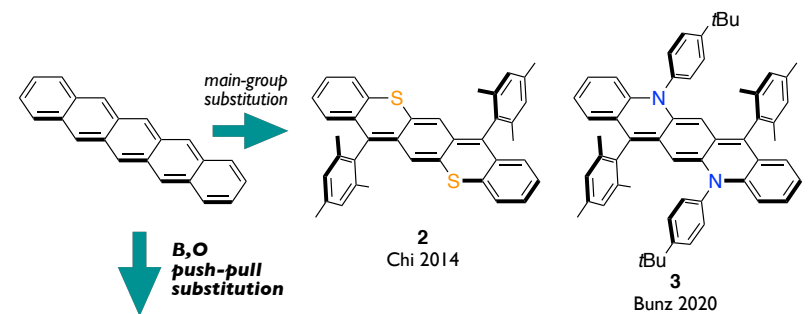

(c) This work

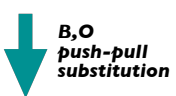

$\stackrel{2}{2}$ Chi 2014

Bunz 2020

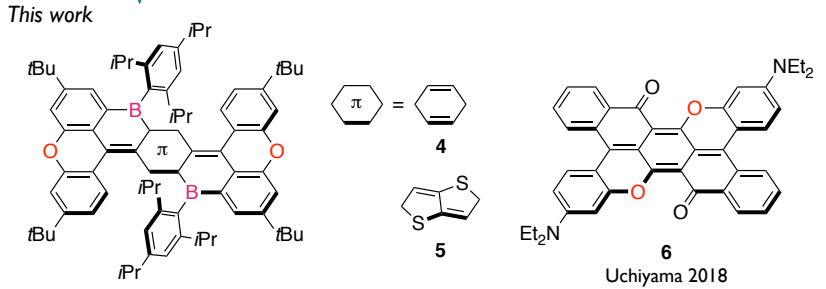

Figure 1. (a) Main-group substitution of an oxygen atom at the 10-position of xanthene dyes and integration of the bora-xanthene scaffold into 1; (b) examples of main-group-substituted 5,12-dihydropentacenes; (c) chemical structures of $\mathrm{B}, \mathrm{O}$-containing heteroacenes and the related compound $\mathbf{6}$.

Acenes, including pentacene, have attracted continuous attention not only in the context of exploring their intrinsic reactivity and properties, ${ }^{[5]}$ but also due to their promising utility in organic (opto)electronics. ${ }^{[6]}$ Various types of structural modifications have been examined, including steric protection with bulky aryl groups at the periphery, ${ }^{[7]}$ incorporation of electronwithdrawing ethynyl groups, ${ }^{[8]}$ and substitution of the skeletal carbon atoms with heteroatoms. ${ }^{[9]} \mathrm{A}$ representative example of the latter modification is 5,12-dihydropentacenes, in which heteroatoms are introduced at the 5,12-positions (Figure 1b). Chi 
and coworkers have synthesized 5,12-dithia-5,12dihydropentacene 2 together with its $\pi$-extended analogues. ${ }^{[10]}$ Bunz and coworkers have synthesized nitrogen analogue $3{ }^{[11]}$ In these scaffolds, the heteroatoms regulate the positions of the aromatic $\pi$-sextet rings at the termini of the pentacene skeleton while enhancing the $p$-quinodimethane character in the central moiety. These modifications result in increased stability and endow the resulting compounds with intriguing photophysical, electrochemical, and semiconducting properties. Despite the intensive studies of these electron-rich heteroacenes, heteroacenes that incorporate electron-deficient atoms, such as boron, remain relatively unexplored. ${ }^{[12]}$ In such $\pi$-systems, the empty $p$ orbitals of the boron atoms should participate in the $\pi$ conjugation, which would strongly affect their electronic structures, particularly the LUMO energy level, and thereby alter their properties.

Although the parent 5,12-dibora-5,12-dihydropentacene 1 itself is difficult to construct from a synthetic point of view, we designed oxygen-bridged analogue 4 as an accessible target molecule (Figure 1c). Using our synthetic route, the central benzene ring can be replaced with other spacer units, such as thienothiophene in $\mathbf{5}$. The compounds thus obtained exhibit significantly red-shifted absorption and emission in the NIR region, reflecting the synergistic push-pull effects of the boron and oxygen atoms. This electronic effect is reminiscent of that in the bis-carbonyl-bridged analogue $\mathbf{6}$, reported by Uchiyama and coworkers, in which two amino groups are introduced as electrondonating groups at the termini. ${ }^{[13]}$ In contrast to 6 , our molecules show much smaller Stokes shifts and significantly narrower emission bandwidths. In this article, we disclose their synthesis, crystal structures, and electrochemical and photophysical properties, together with in-depth elucidation of their unique emission properties.

\section{Results and Discussion}

Incorporation of the xanthyl substructures into the target compounds allowed us to readily synthesize 5,12-dibora-5,12dihydropentacene 4 starting from bis(t-butylphenyl) ether 7 (Scheme 1). The regioselective monolithiation of 7 with $s$ butyllithium followed by treatment with 2,5-dibromoterephthalaldehyde afforded diol 8. The intramolecular FriedelCrafts-type cyclization of $\mathbf{8}$ with $\mathrm{FeCl}_{3}$ produced dixanthyldibromobenzene 9. ${ }^{[14]}$ Subsequent dilithiation, followed by the addition of $\mathrm{Me}_{2} \mathrm{SiHCl}$ produced 10 . The Rh-catalyzed intramolecular cyclization ${ }^{[15]}$ of 10 afforded 9-ring fused 11. Further treatment of the thus obtained silicon-bridged precursor with boron tribromide followed by the addition of 2,4,6triisopropylphenylmagnesium bromide (TipMgBr) successfully furnished $\mathbf{4}$ in $37 \%$ yield as a dark green solid. Compound $\mathbf{4}$ was stable enough to be purified by column chromatography on silica gel and recrystallization under ambient conditions. To evaluate its chemical stability, the change in its UV-vis absorption spectrum in a solution of oxygen-saturated toluene in the dark was monitored. No significant spectral change was observed for $\mathbf{4}$ with the retention of $99 \%$ of the initial intensity of the absorbance even after $18 \mathrm{~h}$ (Figure S1).

Single crystals of 4 suitable for an X-ray crystallographic analysis were grown by slow diffusion of $\mathrm{EtOH}$ into a $\mathrm{CH}_{2} \mathrm{Cl}_{2}$
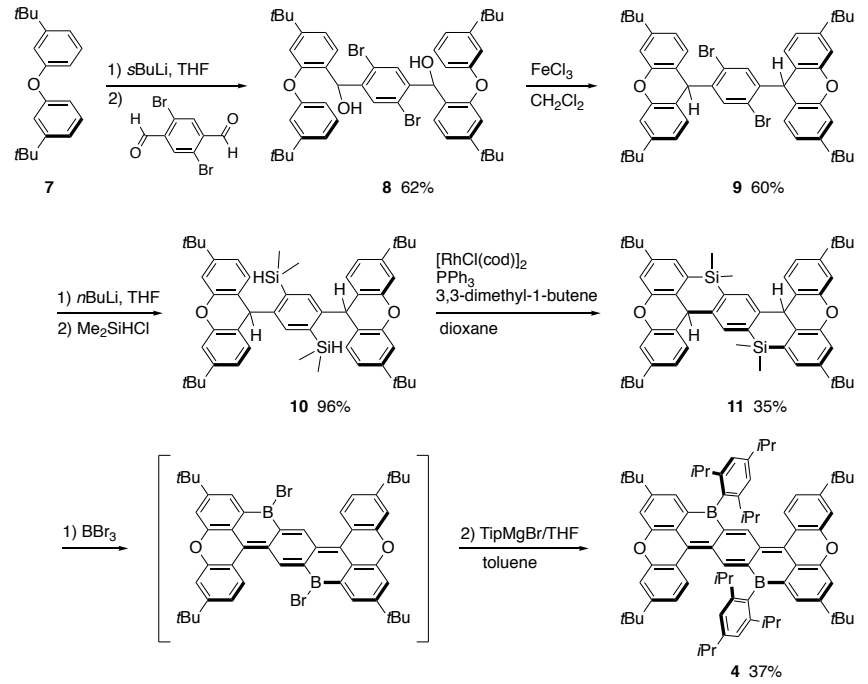

Scheme 1. Synthetic route to 4 .

solution of the compound. As shown in Figure 2, the 9-ring fused skeleton deviates slightly from co-planarity, particularly around the fjord region consisting of the central benzene ring and one of the outer benzene rings; the dihedral angle of $\mathrm{C} 1-\mathrm{C} 2-\mathrm{C} 11-\mathrm{C} 12$ is $31.5^{\circ}$. The Tip group is oriented orthogonally relative to the diborapentacene plane with a dihedral angle of $79.2^{\circ}$. The steric bulk of the Tip groups together with that of the peripheral $t$-butyl groups prevents $\pi$-stacking in the crystal packing.

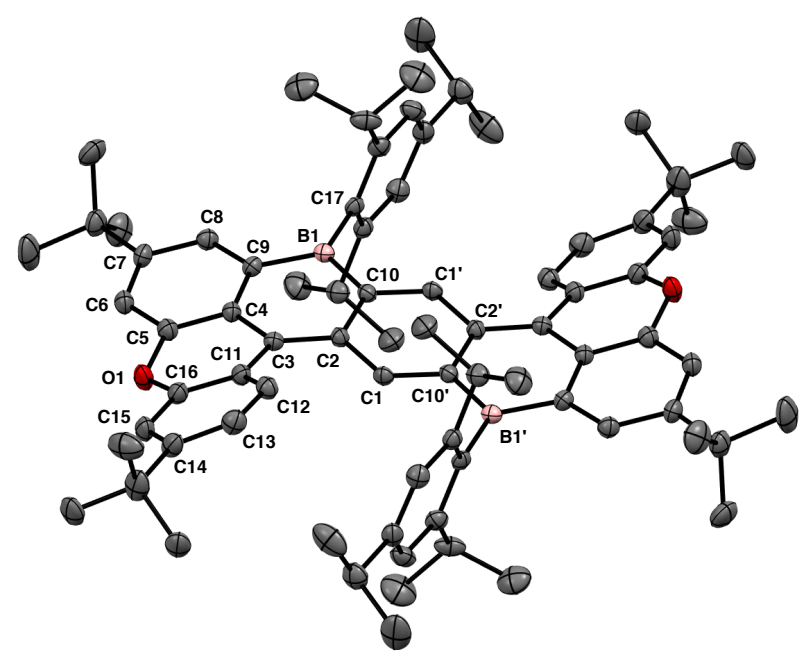

Figure 2. ORTEP drawing of 4 with thermal ellipsoids at $50 \%$ probability; hydrogen atoms are omitted for clarity.

A close inspection of the bond length in the crystal structure gave insight into the inherent character of the diboraacene $\pi$ systems. In 4 , the boron atom adopts a trigonal planar geometry, in which the sum of the $\mathrm{C}-\mathrm{B}-\mathrm{C}$ angles is $360^{\circ}$. The endocyclic $\mathrm{B}-$ $C$ bond is slightly shorter (B1-C9: 1.544(3) $\AA$; B1-C10: 1.543(3) $\AA$ ) than the exocyclic Tip C-B bond (B1-C17: 1.587(3) $\AA$ ). The bond alternation in the four outer benzene rings is relatively small, reflecting a highly aromatic character. In contrast, the central three-ring fused moiety in the diborapentacene skeleton has a $p$ quinodimethane geometry with short C2-C3 (1.402(3) $\AA$ ) and C1C10' bonds $(1.382(3) \AA)$, reflecting a distinct double-bond 
character. It should also be noted here that the peripheral $\mathrm{C} 1-\mathrm{C} 2$ bond $(1.423(3) \AA)$ is shorter than the inner $\mathrm{C} 2-\mathrm{C} 10$ bond (1.461(3) $\AA$ ), which is indicative of more effective conjugation in the peripheral butadiene skeleton as a part of the acene scaffold (vide infra).

Reflecting the quinoidal structure, diboradihydropentacene 4 exhibits intense absorption and emission bands in the NIR region (Figure 3). Thus, in cyclohexane, $\mathbf{4}$ showed a vibronic-structured absorption band with the longest absorption maximum ( $\left.\lambda_{\text {abs }}\right)$ at $770 \mathrm{~nm}$ and a molar absorption coefficient $(\varepsilon)$ exceeding $10^{5} \mathrm{M}^{-1}$ $\mathrm{cm}^{-1}$. In the fluorescence spectrum, 4 showed a sharp emission band in a mirror-image fashion relative to the absorption spectrum, with a maximum emission wavelength $(\lambda \mathrm{em})$ at $791 \mathrm{~nm}$ accompanying a small Stokes shift of $345 \mathrm{~cm}^{-1}(21 \mathrm{~nm})$ and a moderate fluorescence quantum yield $\left(\Phi_{F}\right)$ of $8.9 \%$. When the solvent was changed from cyclohexane to the more polar $\mathrm{CH}_{2} \mathrm{Cl}_{2}$, the absorption spectrum did not show significant change, while the emission spectrum showed a broader red-shifted band $(\lambda \mathrm{em}=$ $855 \mathrm{~nm}$ ) (Table S1 and Figures S2 and S3), which is indicative of some extent of intramolecular-charge-transfer character in the excited state. These photophysical properties are distinct from those of dithia- or diazadihydropentacenes $\left(2: \lambda_{\mathrm{abs}}, 555 \mathrm{~nm} ; \lambda_{\mathrm{em}}\right.$, $617 \mathrm{~nm}$ in $\mathrm{CH}_{2} \mathrm{Cl}_{2} ;{ }^{[10 b]} 3: \lambda_{\mathrm{abs}}, 574 \mathrm{~nm} ; \lambda_{\mathrm{em}}, \sim 590 \mathrm{~nm}$ in $\left.\mathrm{CH}_{2} \mathrm{Cl}_{2}{ }^{[11]}\right)$. The replacement of the sulfur or nitrogen atoms with boron atoms resulted in significantly red-shifted absorption and emission maxima (>200 nm).

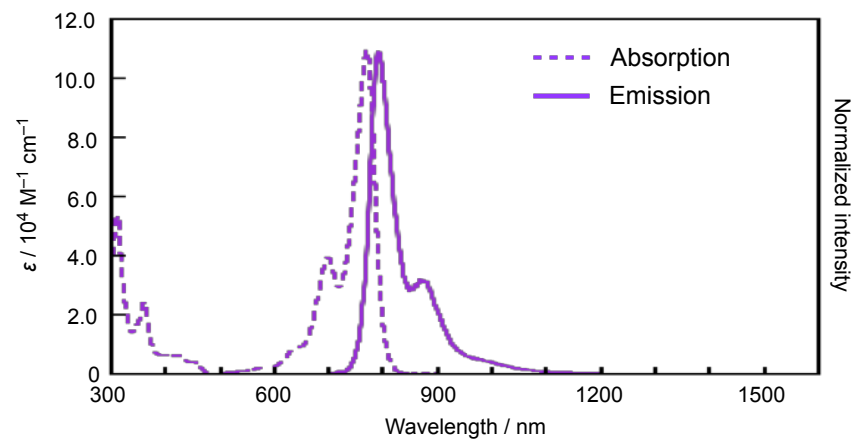

Figure 3. Absorption and emission spectra of $\mathbf{4}$ in cyclohexane.

To elucidate the effect of the boron atoms on the photophysical properties, TD-DFT calculations of model compound $\mathbf{4}^{\prime}$, in which the Tip groups of $\mathbf{4}$ are replaced with mesityl groups and the peripheral $t$-butyl groups are removed for simplification, were conducted at the B3LYP/6-31+G(d) level of theory. Figure 4 a shows a comparison of its electronic structure and electronic transition with those of dithia-, diaza-, and diboradihydropentacene 2', 3', and 1. Compared to those of dithia- and diazadihydropentacene 2 ' and 3 ', the incorporation of the boron atoms in 1 results in significantly decreased $\mathrm{HOMO}$ and LUMO levels. The magnitude of the decrease of the HOMO and LUMO from 2' to 1 are comparable $(\sim 0.7 \mathrm{eV})$. Considering the greater length of the $\mathrm{C} 2-\mathrm{C} 10$ bond compared to that of the $\mathrm{C} 1-$ $\mathrm{C} 2$ bond observed in the crystal structure, the significant changes in the HOMO and LUMO level can be, at least partly, attributed to the orbital interaction in the peripheral butadienylborane moieties (Figure $4 \mathrm{~b}$ ). It should be noted here that a p-orbital of the boron atom interacts with the $\pi$ and $\pi^{*}$ orbitals of the butadiene moiety in an in-phase fashion in the HOMO and LUMO, respectively.
However, this orbital interaction does not significantly affect the HOMO-LUMO gap and, therefore, the calculated absorption wavelength for $\mathbf{1}$ is only slightly longer than that of $2^{\prime}$. In contrast, in oxygen-bridged $4^{\prime}$, the planarized phenyl ether moiety significantly increases the HOMO level while maintaining the LUMO level comparable to that of 1 . Consequently, 4 ' exhibits a significantly red-shifted absorption, while the oscillator strength is not affected. This electronic perturbation can be rationalized in terms of a synergistic push-pull effect between the electrondonating ether moieties and the electron-accepting boron moieties at the periphery of the acene scaffold (Figure $4 \mathrm{~b}$ ). Notably, the distant O---B pair, rather than the near O---B pair, plays a crucial role in generating the push-pull structure. Indeed, comparison of the optimized geometries of $4^{\prime}$ and 1 showed a slightly contracted $\mathrm{C} 1-\mathrm{C} 2$ bond in $\mathbf{4}^{\prime}(1.429 \AA)$ relative to that in 1 (1.442 $\AA$ ), which does not have the donating ether moiety (Figure S8). A similar electronic effect was reported by Uchiyama and coworkers for $\mathbf{6}$, where the push-pull effect of the terminal amino groups and the carbonyl bridges results in NIR absorption and emission. ${ }^{[13]}$ In our molecule, the bridging oxygen atoms instead of terminal amino groups serve as the electron-donating moiety to furnish the NIR absorption. In other words, this push-pull effect provides a versatile modification strategy to render acene skeletons being NIR-active materials. (a)

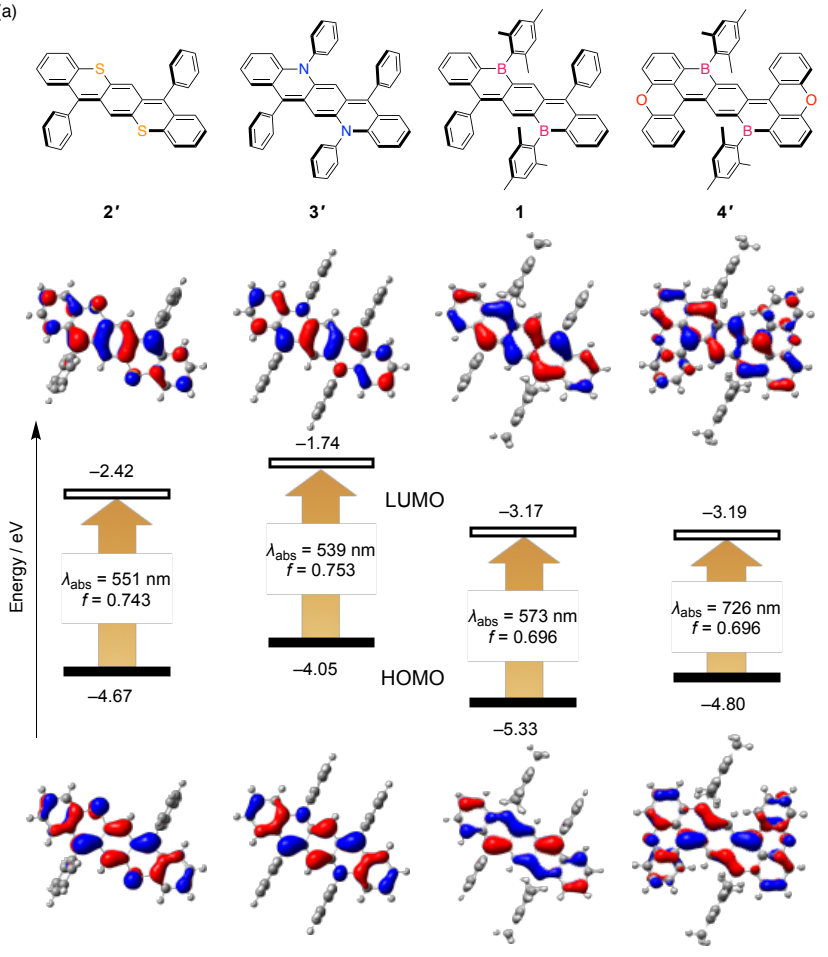

(b)
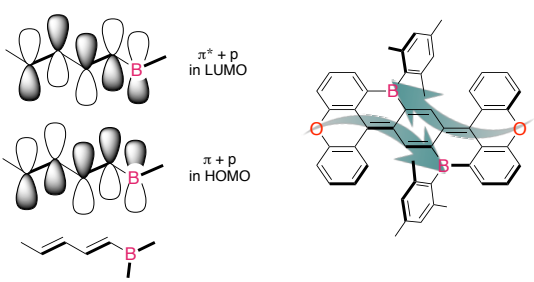

Figure 4. (a) TD-DFT calculations of heteropentacenes 1, 2', 3', and 4' at the B3LYP/6-31+G(d) level of theory and their Kohn-Sham HOMOs and LUMOs. (b) Schematic illustration of the orbital interaction in the butadienylborane substructure in the HOMO and LUMO of 1 (left) and the push-pull effect in 4' (right). 
It is noteworthy that the diboradihydropentacene is isoelectronic with the pentacene dication. While in the latter, the positive charges are delocalized predominantly over the inner hexagon rings (Figure S9), ${ }^{[16]}$ in the former, the boron atoms define the positions of the electron-deficient centers, by which the $p$-quinodimethane character is enhanced, similar to the cases of the dithia- and diaza-counterparts. ${ }^{[10 a, b, 11]}$ In light of the $p$ quinodimethane character of $\mathbf{4}$, this compound can also be regarded as a boron-bridged analogue of Thiele's hydrocarbon. From this point of view, its diradical character is of interest, since a boron atom embedded in a hexagonal ring can stabilize a radical through delocalization of the spin density. ${ }^{[17]}$ However, 4 did not show any ESR signal in benzene, and sharp signals were observed in its ${ }^{1} \mathrm{H}$ NMR spectra in benzene- $d_{6}$ even upon heating to $70{ }^{\circ} \mathrm{C}$ (Figures S4 and S5), indicating a negligible diradical character. The aforementioned push-pull structure may partly affect this characteristic feature.

(a)

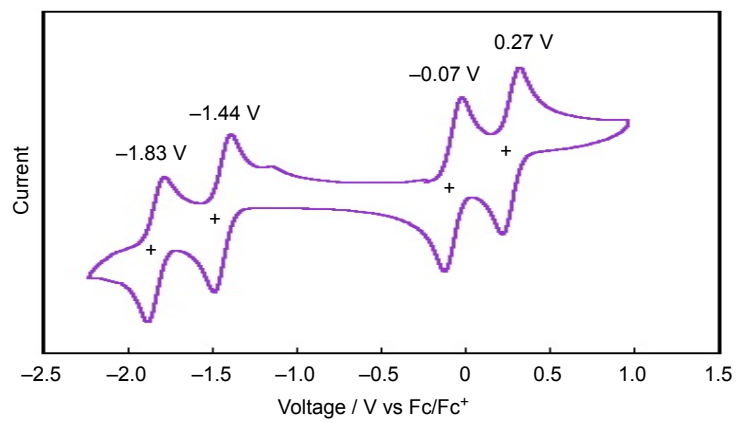

(b)

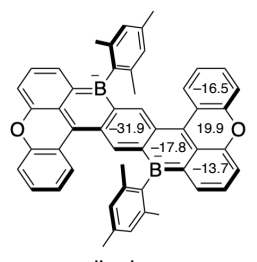

dianion

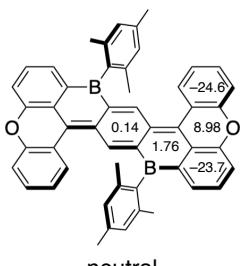

neutral

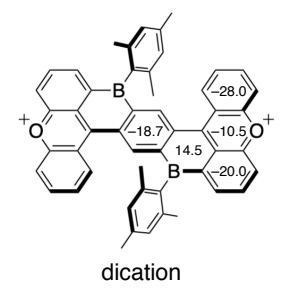

(c)

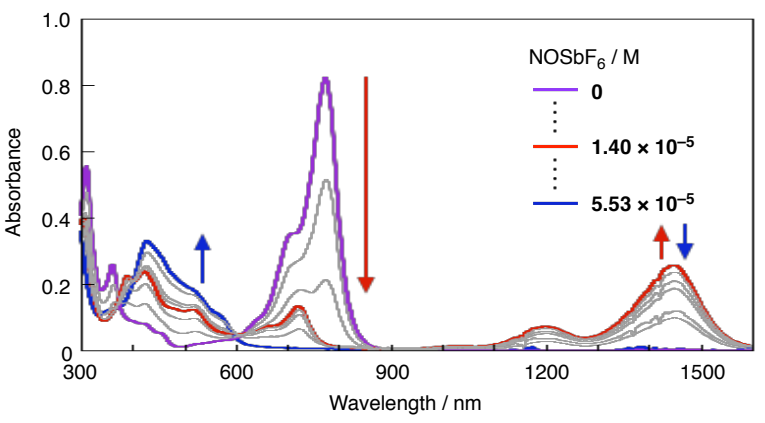

Figure 5. (a) Cyclic voltammogram of $4(1 \mathrm{mM})$ in $\mathrm{CH}_{2} \mathrm{Cl}_{2}$; scan rate: $0.05 \mathrm{~V} \mathrm{~s}$ 1; supporting electrolyte: $\left[n \mathrm{Bu}_{4} \mathrm{~N}\right]\left[\mathrm{PF}_{6}\right](0.1 \mathrm{M})$; all potentials referenced vs. $\mathrm{Fc} / \mathrm{Fc}^{+}$. (b) NICS(1)zz values of the dianion, neutral, and dication species of $4^{\prime}$ calculated at the $\mathrm{HF} / 6-31+\mathrm{G}$ (d) level of theory. (c) Change in the absorption spectrum of $4\left(0.921 \times 10^{-5} \mathrm{M}\right)$ in $\mathrm{CH}_{2} \mathrm{Cl}_{2}$ upon the addition of $\mathrm{NOSbF}_{6}$ in $\mathrm{CH}_{3} \mathrm{CN}$ solution.

Additionally, the dibora-bridged $p$-quinodimethane structure renders the compound multi-redox active. The cyclic voltammogram of $\mathbf{4}$ in $\mathrm{CH}_{2} \mathrm{Cl}_{2}$ exhibited two reversible redox processes for both the reduction and the oxidation with half-wave potentials $\left(E_{1 / 2}\right)$ of $-1.44 \mathrm{~V}$ and $-1.83 \mathrm{~V}$ for the reduction and of $0.07 \mathrm{~V}$ and $0.27 \mathrm{~V}$ for the oxidation ( $\mathrm{vs} \mathrm{Fc} / \mathrm{Fc}^{+}$) (Figure $5 \mathrm{a}$ ). This result contrasts with those for dithia-analogue 2 , which show only one reversible reduction and two reversible oxidation processes. In addition, the less positive oxidation potentials and less negative reduction potentials of $\mathbf{4}$ compared to those of $\mathbf{2}$ indicate a narrow HOMO-LUMO gap, consistent with its absorption and emission in the NIR region. The multi-redox processes observed for $\mathbf{4}$ are reversible for at least 10 cycles, indicating that the generated reduced and oxidized species are stable under the applied measurement conditions. This feature should be relevant to the aromatic character of the reduced and oxidized species. To gain insight into this aspect, nucleus-independent chemical shift (NICS) calculations were carried out at the $\mathrm{HF} / 6-31+\mathrm{G}(\mathrm{d})$ level of theory (Figure $5 b$ ). In the dianion of 4 ', the boron-containing hexagonal ring gains aromatic character with an NICS(1) zz value of $-17.8 \mathrm{ppm}$, while the oxygen-containing hexagon ring has a positive value of $+19.9 \mathrm{ppm}$. On the other hand, the dication of 4 ' shows the opposite trend in aromaticity, with the oxygencontaining hexagonal ring gaining moderate aromaticity with a NICS(1) zz value of $-10.5 \mathrm{ppm}$, while the boron-containing hexagon ring takes on a positive value of $+14.5 \mathrm{ppm}$.

Among the multi-redox processes in $\mathbf{4}$, the stepwise oxidation processes can be monitored in the UV-vis-NIR absorption spectra by chemical oxidation using $\mathrm{NOSbF}_{6}$ (Figure $5 \mathrm{c}$ ). Upon addition of a $\mathrm{CH}_{3} \mathrm{CN}$ solution of $\mathrm{NOSbF}_{6}$ to a $\mathrm{CH}_{2} \mathrm{Cl}_{2}$ solution of 4 , the sharp band of 4 at $\lambda_{\text {abs }}=773 \mathrm{~nm}$ gradually decreased in intensity and a new broad absorption band emerged at $1448 \mathrm{~nm}$. The intensity of the band increased upon increasing the amount of $\mathrm{NOSbF}_{6}$ to ca. 1.5 equiv. Adding more $\mathrm{NOSbF}_{6}$ resulted in an increase in the intensity of the broad absorption band at 400-600 $\mathrm{nm}$ and a decrease in the intensity of the absorption band at 1448 $\mathrm{nm}$. This stepwise change can be attributed to the generation of radical cation $\mathbf{4}^{+\cdot}$ followed by dication $4^{2+}$, which is supported by theoretical calculations (Figure S10). While $4^{+\cdot}$ is isoelectronic with the dication radical of pentacene, the spin density is delocalized over the entire diborapentacene skeleton (Figure S11). Although we also attempted the chemical reduction of 4 with $\mathrm{Cp}^{*}{ }_{2} \mathrm{Co}$, this resulted only in the appearance of a new broad band at $700-1100 \mathrm{~nm}$ without stepwise changes (Figure S7), which hampered a further assignment of this band.

Our robust synthesis further enabled us to synthesize more extended heteroacenes by replacing the central benzene ring in 4 with other spacers. As an example, thienothiophene-connected 10-ring fused heteroacene $\mathbf{5}$ was synthesized (for details, see Scheme S1). An X-ray crystallographic analysis revealed that the 10 -ring fused skeleton has a slightly more planar geometry than 4 due to the reduced steric congestion in the fjord region in $\mathbf{5}$; the dihedral angle $\mathrm{S} 1-\mathrm{C} 1-\mathrm{C} 11-\mathrm{C} 12$ is $25.2^{\circ}$ (Figure 6a). Compound 5 showed reversible two-step redox waves with reduction potentials of $-1.14 \mathrm{~V}$ and $-1.47 \mathrm{~V}\left(\mathrm{vs} \mathrm{Fc} / \mathrm{Fc}^{+}\right)$, which are $0.30 \mathrm{~V}$ and $0.36 \mathrm{~V}$ less negative than those of its benzene counterpart 4 , while the oxidation potentials of $\mathbf{4}$ and $\mathbf{5}$ are comparable (Figure S6). It should also be noted here that the absorption and emission spectra of $\mathbf{5}$ in the NIR region are significantly red-shifted (Figure $6 \mathrm{~b})$. In cyclohexane, $\mathbf{5}$ showed a very sharp and vibronicstructured absorption band at $\lambda_{\text {abs }}=945 \mathrm{~nm}$ and a high $\varepsilon$ value of $1.99 \times 10^{5} \mathrm{M}^{-1} \mathrm{~cm}^{-1}$. In the fluorescence spectrum, $\mathbf{5}$ exhibited a mirror-image emission band at $\lambda_{\mathrm{em}}=952 \mathrm{~nm}$. Despite the long wavelength of the $\lambda_{\mathrm{em}}$ value, 5 retained a fluorescence quantum yield of $2.3 \%$. Moreover, the Stokes shift observed for $\mathbf{5}$ is only 78 $\mathrm{cm}^{-1}(7 \mathrm{~nm})$, and the full width at half maximum (FWHM) of its 
emission band is $309 \mathrm{~cm}^{-1}(28 \mathrm{~nm})$; these values are much smaller than those of 4 (Stokes shift: $345 \mathrm{~cm}^{-1}, 21 \mathrm{~nm}$; FWHM; $771 \mathrm{~cm}^{-1}, 49 \mathrm{~nm}$ ). Such sharp NIR emission band is reminiscent of the emissions of rare-earth metal complexes. These distinct spectral features should be due to its rigid and more planar structure compared to that of $\mathbf{4}$ (vide supra).

(a)
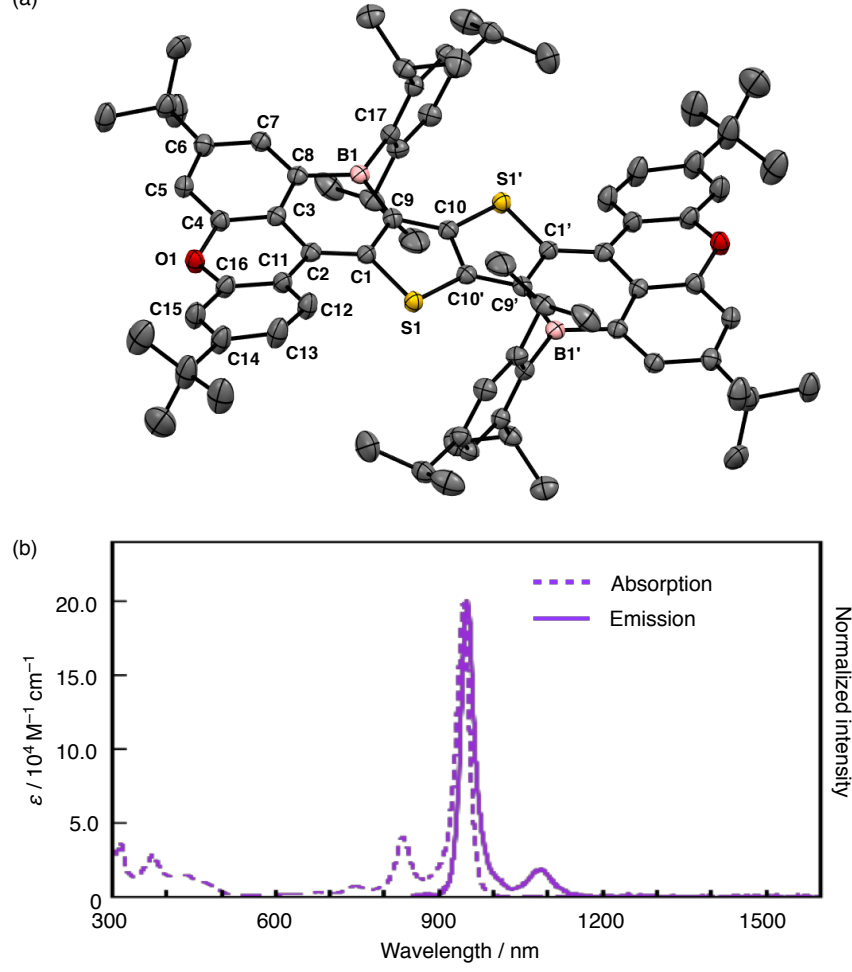

Figure 6. (a) ORTEP drawing of $\mathbf{5}$ with thermal ellipsoids at $50 \%$ probability; hydrogen atoms and $\mathrm{CH}_{2} \mathrm{Cl}_{2}$ molecules are omitted for clarity. (b) Absorption and emission spectra of $\mathbf{5}$ in cyclohexane.

To gain in-depth insight into the unique emission spectrum of 5, a Franck-Condon analysis of the transition from the zero-point vibrational energy level in $S_{1}$ to $S_{0}$ was conducted. Model compound 5", in which the Tip groups in $\mathbf{5}$ are simplified with mesityl groups, was examined at the B3LYP/6-31+g(d) level of theory and compared to 4 ", which has the same substituent set as 5 ". The simulated fluorescence spectra were consistent with the experimentally observed spectra for $\mathbf{4}$ and $\mathbf{5}$ (Figure 7a). Both 4 and 5 exhibited distinct vibronic structures with comparable differences between the first and second shortest bands $(4,1121$ $\left.\mathrm{cm}^{-1} ; \mathbf{5}, 1305 \mathrm{~cm}^{-1}\right)$. The Franck-Condon analysis showed that the second shortest bands are attributed to the stretching vibrational modes of the $\mathrm{C}-\mathrm{C}$ bonds along the long axis of the acene skeletons in $\mathrm{S}_{0}$. In contrast, a crucial difference between 4 " and 5 " was observed in the composition of their first emission bands (Figure 7a). While in benzene-connected 4", several transitions from the zero-point vibrational energy level in $S_{1}$ to vibrational energy levels coupled with twisting vibrational modes (such as \#23, Figure $7 \mathrm{~b}$ ) in $\mathrm{S}_{0}$ contribute to the first emission band in addition to the zero-to-zero transition, the contribution of these transitions relevant to the twisting vibrational modes are trivial in thienothiophene-connected 5" (Tables S2, S3 and Figures S13, $\mathrm{S14}$ ). This is the origin of the significantly smaller FWHM value observed for $\mathbf{5}$, and the reduced steric congestion in the fjord region of $\mathbf{5}$ should be responsible for this feature. This result implies the importance of the 5-membered heteroarene as a spacer for the design of emissive extended heteroacene skeletons.

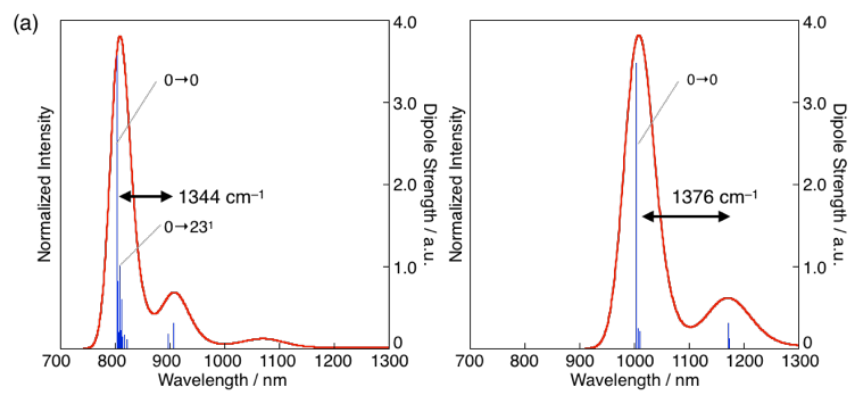

(b)

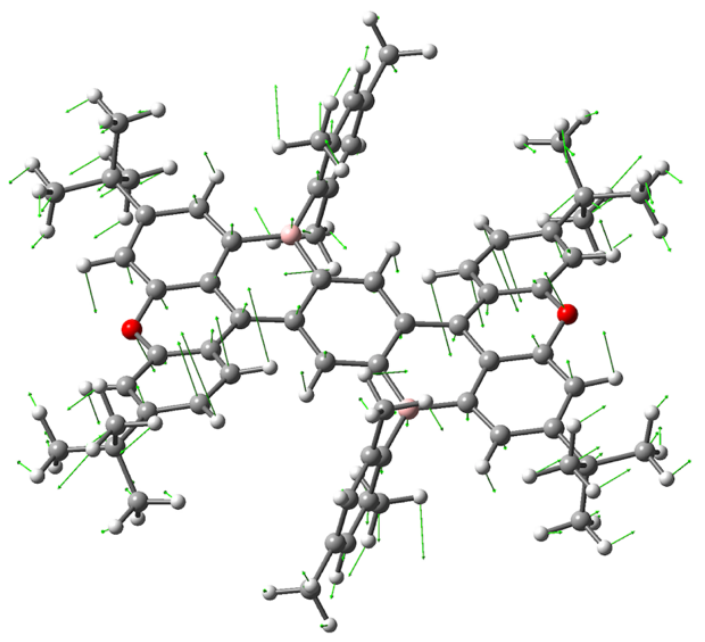

Figure 7. (a) Simulated fluorescence spectra obtained using Franck-Condon calculations (red line) and dipole strengths of the transitions (blue lines) for 4 " (left) and 5" (right). (b) A representative twisting vibrational mode (\#23) of 4 " in So.

\section{Conclusion}

In conclusion, we succeeded in synthesizing two boroncontaining heteroacenes, $\mathbf{4}$ and $\mathbf{5}$, via the borylation of the corresponding silicon-bridged precursors. A thorough examination of their crystal structures as well as their electrochemical and photophysical properties showed that the combination of the electron-donating planarized phenyl ether moieties and the electron-deficient diboradihydropentacene moieties gives rise to a push-pull electronic effect that leads to reversible multi-redox behavior as well as intense absorption and sharp emission in the NIR region. It should be noted here that the impact of the replacement of the central benzene ring with a thienothiophene spacer resulted in a red-shifted emission $\left(\lambda_{\mathrm{em}}=\right.$ $952 \mathrm{~nm}$ ) accompanied by the small Stokes shift and FWHM values. These results demonstrate that the combined design strategy involving the incorporation of electron-deficient boron atoms and the creation of a push-pull structure while introducing a heteroarene spacer represents a powerful strategy to produce a NIR-emissive acene-type $\pi$-scaffold. We are currently working on expanding this design principle to produce other attractive heteroacenes. 


\section{Acknowledgements}

This work was supported by KAKENHI grants $18 \mathrm{H} 03909$, $18 \mathrm{H} 05261$, and 20K15258 from the Japan Society for the Promotion of Science (JSPS). The authors thank Prof. K. Awaga, and Dr. Y. Shuku (Nagoya Univ.) for the EPR spectroscopy measurement, Prof. T. Yanai and Mr. N. Inai (Nagoya Univ.) for the discussion about the Franck-Condon analysis, and Prof. $\mathrm{H}$. Shinokubo and Ms. A. Takiguchi (Nagoya Univ.) as well as Dr. A. Konishi (Osaka Univ.) for valuable discussions. M. I. and M. S. thank the JSPS for a Research Fellowship for Young Scientists and the "Graduate Program of Transformative Chem-Bio Research" at Nagoya University, supported by MEXT (WISE Program).

\section{Conflict of interest}

The authors declare no conflict of interest.

Keywords: boron $\cdot$ heteroacene $\cdot$ near infrared fluorescence $•$ push-pull effect $\bullet$ Franck-Condon analysis

[1] For recent reviews, see: a) M. Stępień, E. Gońka, M. Żyła, N. Sprutta, Chem. Rev. 2017, 117, 3479-3716; b) M. Hirai, N. Tanaka, M. Sakai, S Yamaguchi, Chem. Rev. 2019, 119, 8291-8331; c) K. Dhbaibi, L. Favereau, J. Crassous, Chem. Rev. 2019, 119, 8846-8953; d) X.-Y. Wang, X. Yao, A. Narita, K. Müllen, Acc. Chem. Res. 2019, 52, 2491 2505.

[2] For reviews, see: a) T. Baumgartner, R. Réau, Chem. Rev. 2006, 106, 4681-4727; b) A. Fukazawa, S. Yamaguchi, Chem. Asian J. 2009, 4, 1386-1400; c) A. Escande, M. J. Ingleson, Chem. Commun. 2015, 51, 6257-6274; d) S. M. Parke, M. P. Boone, E. Rivard, Chem. Commun 2016, 52, 9485-9505; e) L. Ji, S. Griesbeck, T. B. Marder, Chem. Sci. 2017, 8, 846-863; f) E. v. Grotthuss, A. John, T. Kaese, M. Wagner, Asian J. Org. Chem. 2018, 7, 37-53; g) H. Helten, Chem. Asian J. 2019, 14, 919-935; h) S. K. Mellerup, S. Wang, Chem. Soc. Rev. 2019, 48, 3537-3549; i) X. Yin, J. Liu, F. Jäkle, Chem. Eur. J. 2021, 27, 2973-2986.

[3] a) J. V. Jun, D. M. Chenoweth, E. J. Petersson, Org. Biomol. Chem. 2020 18, 5747-5763; b) M. R. Detty, P. N. Prasad, D. J. Donnelly, T. Ohulchanskyy, S. L. Gibson, R. Hilf, Bioorg. Med. Chem. 2004, 12, 2537-2544; c) B. Calitree, D. J. Donnelly, J. J. Holt, M. K. Gannon, C. L. Nygren, D. K. Sukumaran, J. Autschbach, M. R. Detty, Organometallics 2007, 26, 6248-6257; d) M. Fu, Y. Xiao, X. Qian, D. Zhao, Y. Xu, Chem Commun. 2008, 1780-1782; e) K. Kolmakov, V. N. Belov, C. A. Wurm B. Harke, M. Leutenegger, C. Eggeling, S. W. Hell, Eur. J. Org. Chem. 2010, 3593-3610; f) T. Egawa, Y. Koide, K. Hanaoka, T. Komatsu, T. Terai, T. Nagano, Chem. Commun. 2011, 47, 4162-4164; g) Y. Koide Y. Urano, K. Hanaoka, T. Terai, T. Nagano, ACS Chem. Biol. 2011, 6, 600-608; h) J. B. Grimm, A. J. Sung, W. R. Legant, P. Hulamm, S. M Matlosz, E. Betzig, L. D. Lavis, ACS Chem. Biol. 2013, 8, 1303-1310; i) X. Chai, X. Cui, B. Wang, F. Yang, Y. Cai, Q. Wu, T. Wang, Chem. Eur J. 2015, 21, 16754-16758; j) H. Nie, J. Jing, Y. Tian, W. Yang, R. Zhang, X. Zhang, ACS Appl. Mater. Interfaces 2016, 8, 8991-8997; k) J. Liu, Y.Q. Sun, H. Zhang, H. Shi, Y. Shi, W. Guo, ACS Appl. Mater. Interfaces 2016, 8, 22953-22962; I) A. Fukazawa, S. Suda, M. Taki, E. Yamaguchi, M. Grzybowski, Y. Sato, T. Higashiyama, S. Yamaguchi, Chem. Commun. 2016, 52, 1120-1123; m) T. Ikeno, T. Nagano, K. Hanaoka, Chem. Asian J. 2017, 12, 1435-1446; n) T. Hirayama, A. Mukaimine, K. Nishigaki, H. Tsuboi, S. Hirosawa, K. Okuda, M. Ebihara, H. Nagasawa, Dalton Trans. 2017, 46, 15991-15995; o) G. Dejouy, M. Laly, I. E. Valverde, A. Romieu, Dyes Pigm. 2018, 159, 262-274; p) M. Grzybowski, M. Taki, K. Kajiwara, S. Yamaguchi, Chem. Eur. J. 2020, 26, 7912-7917.

[4] N. Ando, H. Soutome, S. Yamaguchi, Chem. Sci. 2019, 10, 7816-7821.
[5] a) H. F. Bettinger, C. Tönshoff, Chem. Rec. 2015, 15, 364-369; b) R. Dorel, A. M. Echavarren, Eur. J. Org. Chem. 2017, 14-24; c) R. Einholz, T. Fang, R. Berger, P. Grüninger, A. Früh, T. Chassé, R. F. Fink, H. F. Bettinger, J. Am. Chem. Soc. 2017, 139, 4435-4442; d) S. Dong, A. Ong, C. Chi, J. Photochem. Photobiol. C 2019, 38, 27-46; e) R. Bhatia, D. Wadhawa, G. Gurtu, J. Gaur, D. Gupta, J. Saudi Chem. Soc. 2019, 23, 925-937.

[6] For reviews, see: a) M. Bendikov, F. Wudl, D. F. Perepichka, Chem. Rev. 2004, 104, 4891-4946; b) J. E. Anthony, Chem. Rev. 2006, 106, 50285048; c) J. E. Anthony, Angew. Chem. Int. Ed. 2008, 47, 452-483; d) M. B. Smith, J. Michl, Chem. Rev. 2010, 110, 6891-6936; e) Z. Sun, Q. Ye, C. Chi, J. Wu, Chem. Soc. Rev. 2012, 41, 7857-7889; f) Q. Ye, C. Chi, Chem. Mater. 2014, 26, 4046-4056.

[7] a) B.-B. Jang, S. H. Lee, Z. H. Kafafi, Chem. Mater. 2006, 18, 449-457; b) Y.-M. Wang, N.-Y. Fu, S.-H. Chan, H.-K. Lee, H. N. C. Wong, Tetrahedron 2007, 63, 8586-8597; c) I. Kaur, W. Jia, R. P. Kopreski, S. Selvarasah, M. R. Dokmeci, C. Pramanik, N. E. McGruer, G. P. Miller, J. Am. Chem. Soc. 2008, 130, 16274-16286.

[8] a) J. E. Anthony, D. L. Eaton, S. R. Parkin, Org. Lett. 2002, 4, 15-18; b) M. M. Payne, S. R. Parkin, J. E. Anthony, J. Am. Chem. Soc. 2005, 127, 8028-8029; c) D. Chun, Y. Cheng, F. Wudl, Angew. Chem. Int. Ed. 2008, 47, 8380-8385; d) B. Purushothaman, S. R. Parkin, J. E. Anthony, Org. Lett. 2010, 12, 2060-2063; e) H. Qu, C. Chi, Org. Lett. 2010, 12, 33603363; f) B. Purushothaman, M. Bruzek, S. R. Parkin, A.-F. Miller, J. E. Anthony, Angew. Chem. Int. Ed. 2011, 50, 7013-7017; g) W. Fudickar, T. Linker, J. Am. Chem. Soc. 2012, 134, 15071-15082; h) G. Dai, J. Chang, J. Luo, S. Dong, N. Aratani, B. Zheng, K.-W. Huang, H. Yamada, C. Chi, Angew. Chem. Int. Ed. 2016, 55, 2693-2696.

[9] a) T. Agou, J. Kobayashi, T. Kawashima, Org. Lett. 2006, 8, 2241-2244; b) W. L. Kalb, A. F. Stassen, B. Batlogg, U. Berens, B. Schmidhalter, F. Bienewald, A. Hafner, T. Wagner, J. Appl. Phys. 2009, 105, 043705; c) P. G. Campbell, A. J. V. Marwitz, S.-Y. Liu, Angew. Chem. Int. Ed. 2012, 51, 6074-6092; d) U. H. F. Bunz, J. U. Engelhart, B. D. Lindner, M. Schaffroth, Angew. Chem. Int. Ed. 2013, 52, 3810-3821; e) Q. Miao, Adv. Mater. 2014, 26, 5541-5549; f) U. H. F. Bunz, Acc. Chem. Res. 2015, 48, 1676-1686; g) X. Shi, C. Chi, Chem. Rec. 2016, 16, 1690-1700; h) J. Li, Y. Shen, J. Wan, X. Yu, Q. Zhang, Eur. J. Org. Chem. 2018, 33753390; i) S. Dong, T. Y. Gopalakrishna, Y. Han, H. Phan, T. Tao, Y. Ni, G. Liu, C. Chi, J. Am. Chem. Soc. 2019, 141, 62-66; j) J. J. C. Lee, S. Dong, A. Ong, Y. Han, J. Wu, C. Chi, Org. Lett. 2021, 23, 3027-3031; k) J. J. C. Lee, C. Chi, J. Wu, ChemPlusChem 2021, https://doi.org/10.1002/cplu.202100098.

[10] a) Q. Ye, J. Chang, X. Shi, G. Dai, W. Zhang, K.-W. Huang, C. Chi, Org. Lett. 2014, 16, 3966-3969; b) S. Dong, T. S. Herng, T. Y. Gopalakrishna, H. Phan, Z. L. Lim, P. Hu, R. D. Webster, J. Ding, C. Chi, Angew. Chem. Int. Ed. 2016, 55, 9316-9320; c) Y. Chen, H. Kueh, T. Y. Gopalakrishna, S. Dong, Y. Han, C. Chi, Org. Lett. 2019, 21, 3127-3130.

[11] G. Xie, V. Brosius, J. Han, F. Rominger, A. Dreuw, J. Freudenberg, U. H. F. Bunz, Chem. Eur. J. 2020, 26, 160-164.

[12] a) J. Chen, J. W. Kampf, A. J. Ashe III, Organometallics 2008, 27, 36393641 ; b) T. K. Wood, W. E. Piers, B. A. Keay, M. Parvez, Angew. Chem. Int. Ed. 2009, 48, 4009-4012; c) A. Caruso, Jr., M. A. Siegler, J. D. Tovar, Angew. Chem. Int. Ed. 2010, 49, 4213-4217; d) T. K. Wood, W. E. Piers, B. A. Keay, M. Parvez, Chem. Eur. J. 2010, 16, 12199-12206; e) S. Kirschner, J.-M. Mewes, M. Bolte, H.-W. Lerner, A. Dreuw, M. Wagner, Chem. Eur. J. 2017, 23, 5104-5116; f) A. John, M. Bolte, H.-W. Lerner, G. Meng, S. Wang, T. Peng, M. Wagner, J. Mater. Chem. C 2018, 6, 10881-10887; g) J. Radtke, K. Schickedanz, M. Bamberg, L. Menduti, D. Schollmeyer, M. Bolte, H.-W. Lerner, M. Wagner, Chem. Sci. 2019, 10, 9017-9027.

[13] Y. Okamoto, M. Tanioka, A. Muranaka, K. Miyamoto, T. Aoyama, X. Ouyang, S. Kamino, D. Sawada, M. Uchiyama, J. Am. Chem. Soc. 2018, 140, 17857-17861.

[14] S. K. Das, R. Singh, G. Panda, Eur. J. Org. Chem. 2009, 4757-4761.

[15] a) T. Ureshino, T. Yoshida, Y. Kuninobu, K. Takai, J. Am. Chem. Soc. 2010, 132, 14324-14326; b) M. Murai, R. Okada, A. Nishiyama, K. Takai, Org. Lett. 2016, 18, 4380-4383; c) M. Murai, R. Okada, S. Asako, K. Takai, Chem. Eur. J. 2017, 23, 10861-10870; d) D. Zhou, Y. Gao, B. Liu, Q. Tan, B. Xu, Org. Lett. 2017, 19, 4628-4631; e) T. Shibata, N. Uno, T. 
Sasaki, H. Takano, T. Sato, K. S. Kanyiva, J. Org. Chem. 2018, 83 3426-3432.

[16] a) D. A. Forsyth, G. A. Olah, J. Am. Chem. Soc. 1976, 98, 4086-4090; b) R. Einholz, H. F. Bettinger, Angew. Chem. Int. Ed. 2013, 52, 98189820; c) S. Schundelmeier, B. Speiser, H. F. Bettinger, R. Einholz, ChemPhysChem 2017, 18, 2266-2278; d) B. Shen, T. Geiger, R. Einholz, F. Reicherter, S. Schundelmeier, C. Maichle-Mössmer, B. Speiser, H. F. Bettinger, J. Org. Chem. 2018, 83, 3149-3158.

[17] T. Kushida, S. Shirai, N. Ando, T. Okamoto, H. Ishii, H. Matsui, M. Yamagishi, T. Uemura, J. Tsurumi, S. Watanabe, J. Takeya, S. Yamaguchi, J. Am. Chem. Soc. 2017, 139, 14336-14339. 